\title{
Optimization of the Fermentation Media and Parameters for the Bio-control Potential of Trichoderma longibrachiatum T6 Against Nematodes
}

\author{
Shuwu Zhang ${ }^{1,2,3}$, Yantai Gan', Jia Liu' ${ }^{2,3}$, Jingjiang Zhou ${ }^{2,3}$ and Bingliang $X u^{1,2,3 *}$ \\ ' Gansu Provincial Key Laboratory of Arid Land Crop Science, Gansu Agricultural University, Lanzhou, China, ${ }^{2}$ College \\ of Plant Protection, Gansu Agricultural University, Lanzhou, China, ${ }^{3}$ Biocontrol Engineering Laboratory of Crop Diseases \\ and Pests of Gansu Province, Lanzhou, China, ${ }^{4}$ Agriculture and Agri-Food Canada, Switt Current Research \\ and Development Centre, Saskatchewan, SK, Canada
}

OPEN ACCESS

Edited by:

Anindya Chanda,

Mycologics LLC, United States

Reviewed by:

Abdelfattah A. Dababat, International Maize and Wheat Improvement Center, Mexico Gerardo Díaz-Godínez, Autonomous University of Tlaxcala, United States

*Correspondence: Bingliang Xu xubl@gsau.edu.cn

Specialty section: This article was submitted to Fungi and Their Interactions,

a section of the journal

Frontiers in Microbiology

Received: 29 June 2020 Accepted: 03 September 2020 Published: 30 September 2020

Citation:

Zhang S, Gan Y, Liu J, Zhou J and Xu B (2020) Optimization of the Fermentation Media and Parameters for the Bio-control Potential of Trichoderma longibrachiatum T6 Against Nematodes.

Front. Microbiol. 11:574601. doi: 10.3389/fmicb.2020.574601
The cereal cyst nematode Heterodera avenae is one of the important soil-borne pathogens of cereal crops and causes high yield losses worldwide. Trichoderma spp. formulations are applied as commercial bio-control agents against soil-borne plant pathogens such as $\mathrm{H}$. avenae. However, the relationship between Trichoderma longibrachiatum fermentation parameters and its bio-control potential against $H$. avenae has not been exclusively established. In the present study, the effect of 10 different fermentation media and conditions on the nematicidal activity of T. longibrachiatum T6 (T6) was evaluated with a single-factor method and a Plackett-Burman design, and the interaction between different fermentation parameters was investigated by a Box-Behnken design. The variables for enhancing the nematicidal activity of T6 culture filtrates were explored and optimized using response surface methodology (RSM). The Minor Medium (MM) plus wheat bran-2 medium was found to be the most effective fermentation medium for T6 culture filtrates against the second stage juveniles (J2s) of $H$. avenae. The maximum mortality of the J2s was obtained using the T6 culture filtrates under the following fermentation conditions: initial $\mathrm{pH} 6,28^{\circ} \mathrm{C}$ culture temperature, $180 \mathrm{rpm}$ rotating speed, $60 \mathrm{ml}$ of fermentation media, 7 days of incubation time, and $1 \mathrm{ml}$ of inoculation volumes. Among these parameters, the initial $\mathrm{pH}$, inoculation volume, and incubation day were identified as the most significant parameters and critical independent variables for enhancing the nematicidal activity of the T6 culture filtrates. After further optimizations based on statistical predictions, the highest nematicidal activity $(92.42 \%)$ was obtained with the T6 culture filtrates fermented under an initial $\mathrm{pH}$ of 6.06 , an inoculation volume of $1.62 \mathrm{ml}$, and an incubation time of 7.15 days. The nematicidal activity was increased approximately by as high as $1.07 \%$ compared with that before optimization. Bio-control efficacy of T6 culture filtrates was $83.88 \%$ at the $70^{\text {th }}$ day after wheat seeds sowing in greenhouse experiments. The results from 
the validation experiments agreed with the model predictions. Our study has improved the bio-control potential of Trichoderma spp. against the plant-parasitic nematodes $H$. avenae and provided a cost-efficient bio-resource in the future development of novel bio-control agents.

Keywords: Trichoderma species, Heterodera avenae, nematicidal activity, fermentation media and conditions, Plackett-Burman design, Box-Behnken design, response surface methodology

\section{INTRODUCTION}

The cereal cyst nematode (CCN, Heterodera avenae) is a plant pathogen found in cereal crops in more than 30 countries (Nicol et al., 2003; Jones et al., 2013; Baklawa et al., 2017). The pathogen causes significant crop yield losses (Long et al., 2012), particularly of rainfed cereals (Nicol and Rivoal, 2008). In China, H. avenae is distributed throughout nearly all cereal-growing areas including 13 provinces and autonomous regions (Peng et al., 2009; Niu et al., 2016), where the average yield loss due to $H$. avenae damage was estimated to range from 20 to 30\% (Peng et al., 2009). Similarly, in Pakistan, Saudi Arabia, Australia, and United States, the crop yield losses due to CCNs were, respectively, 15-20, 40-90, 23-50, and 24\% (Nicol et al., 2003; Smiley et al., 2005).

Strategies to manage plant parasitic nematodes in cropping systems have been mainly relied on chemical nematicides (Huang et al., 2014); such a method often causes concerns to environmental sustainability because of chemical pollution. Biomanagement strategies have recently become a more preferred approach to reduce chemical hazards and to conserve the biodiversity of microbial communities (Sharma et al., 2014). Thus, the development of bio-control agents for plant diseases in agriculture has attracted more attention to minimize the use of chemical nematicides (Sergio, 2011). Some beneficial microorganisms, such as nematophagous bacterial and fungal species, are considered as ecologically friendly bio-control agents for the control of nematodes (Jatala, 1986). For example, nematode-trapping fungi, parasitic fungi, and pathogenic fungi are important parasites and predators as natural enemies against nematodes (Siddiqui and Mahmood, 1996; Kerry, 2001). The entomopathogenic fungi of Paecilomyces and Pochonia genus in nematode-suppressive soils have also been reported to have potential to combat plant parasitic nematodes (Nitao et al., 2002; Sharon et al., 2007; Mukhtar et al., 2013).

Recently, there has been an increasing research interest in applying microbial fermentations to manage plant parasitic nematodes worldwide (Khan et al., 2004; Yang et al., 2007). A growing number of studies have been devoted to analyze the potential of extracellular hydrolytic enzymes and secondary metabolites produced by some bio-control microorganisms to control target nematodes (Yang et al., 2016; Sharma et al., 2017). Studies have shown that Trichoderma spp. plays an important role in the development of bio-control agents because they are widely distributed, and mycotrophically filamentous and fastgrowing fungi in soil (Harman et al., 2004). Trichoderma species,

Abbreviations: J2s, second stages juveniles; PDA, potato dextrose agar; RSM, response surface methodology; T6, Trichoderma longibrachiatum T6. such as T. harzianum, T. lignorum, T. koningii, T. virens, and T. viride, have been applied as bio-control agents to suppress the populations of Meloidogyne spp. (Khan and Saxena, 1997; Spiegel and Chet, 1998; Sharon et al., 2001; Suarez and Llobell, 2004). It was shown that the culture filtrates of $T$. virens G1-3 could inhibit the egg hatching and cause second stage juveniles (J2s) mortality in M. incognita (Meyer et al., 2001). However, there is little information in the process of microbial fermentation regarding the components of fermentation medium and conditions used in obtaining these microorganisms and the relationship between the parameters in the process of microbial fermentation and the microorganisms' ability against plant parasitic nematodes. Also, there is an urgent need of information on how to improve the bioactivity of the microorganisms against the nematodes.

Response surface methodology (RSM) has been reported as one of the preferred amenable approaches for determining the best culture conditions and the most effective components of the culture medium with a minimum number of experiments (Larentis et al., 2014; El-Naggar et al., 2016). In some cases, the RSM approach can help to prevent the possible misinterpretation of results when different variables interact with each other (Araujo and Brereton, 1996; Baş and Boyaci, 2007). In other cases, this widely used statistical technique can assist the enhancement of bioprocess optimization with the ability to circumvent the impediments associated with conventional methods (Cui et al., 2006).

In our previous work, we found that the strain of T. longibrachiatum T6 (T6) had a significant parasitic and lethal effect on the nematodes of $H$. avenae and $M$. incognita with a great potential to be used as a bio-control agent. However, the effectiveness of T6 culture filtrates against $H$. avenae J2s varies largely with fermentation media and conditions used (Zhang et al., 2014, 2015). There is a practical challenge in the development of the best filtrates and optimal fermentation conditions under which the nematicidal activity against $H$. avenae J2s can be assessed quantitatively.

The objectives of the present study, therefore, were to (i) maximize the nematicidal activity of T6 culture filtrates against $H$. avenae by evaluating the effect of different fermentation media and parameters on $H$. avenae mortality using the onefactor-at-a-time method and the Plackett-Burman design, and (ii) optimize the critical fermentation parameters to maximize the nematicidal activity of T6 culture filtrates using the RSM method. It is expected that the optimized assessment methodology will facilitate the development of commercial products for $H$. avenae bio-control. 


\section{MATERIALS AND METHODS}

\section{Fungal Strain, Nematode Inoculum, and Media Preparation}

The strain of T. longibrachiatum T6 (T6, CGMCC No.13183) was originally isolated from rhizosphere soil in Gansu, China (Zhang et al., 2017), and the spore suspension of the strain was prepared and stored in $20 \%$ glycerol at $-80^{\circ} \mathrm{C}$ in the Laboratory of Plant Pathology, Gansu Agricultural University.

$H$. avenae cysts were isolated using the "Flotation separation" method (Long et al., 2012) from the soil samples collected from a wheat field in Xingyang, Henan province, China. Freshly hatched J2s were obtained following the procedure of Zhang et al. (2017). The suspension for inoculation was prepared at the concentration of $2 \pm 1 \mathrm{~J} 2 \mathrm{~s}$ per $10 \mu \mathrm{l}$.

Ten different induction media (A, B, C, D, E, F, G, H, I, and J) (Table 1) were prepared and used to screen the optimum fermentation media. Each of these media (1 L) contains different compounds and is assumed to be beneficial for microorganisms against plant pathogens.

\section{Preparation of T. longibrachiatum T6 Culture Filtrates}

The strain of T6 was cultured initially on potato dextrose agar (PDA) in petri dishes at $25^{\circ} \mathrm{C}$ for 7 days under $16 / 8 \mathrm{~h}$ day/night conditions. The spore suspension was prepared following the procedures of Zhang et al. (2014) with minor modifications. The density of the spores was prepared to $1.0 \times 10^{6}$ spores per milliliter and stored at $4^{\circ} \mathrm{C}$. The fermentation was performed by inoculating $1 \mathrm{ml}$ of the spore suspension in a $150 \mathrm{ml}$ Erlenmeyer flask that contains $60 \mathrm{ml}$ of 1 of 10 testing media and incubated on a rotary shaker at $180 \mathrm{rpm}$ and $25^{\circ} \mathrm{C}$ for 5 days. The $\mathrm{pH}$ of the culture medium was adjusted to 6.0 by adding appropriate amounts of $\mathrm{HCl}$ or $\mathrm{KOH}$ prior to sterilization. Each medium was replicated six times. After 5 days of incubation, the culture broths from different replications were mixed and filtered through Whatman No.1 filter paper. The culture filtrates were used as stock solutions for determining the effect of culture media on the nematicidal activity of T6 strain.

\section{The Nematicidal Activity Assay of T6 Culture Filtrates}

$H$. avenae $\mathrm{J} 2 \mathrm{~s}$ and the stock solutions of T6 culture filtrates were used to assay the nematicidal activity in vitro against the J2s of $H$. avenae. Ninety milliliters of the stock solutions were mixed with two to three J2s in each well of a 96-well sterilized cell culture plate. The wells containing sterile water without T6 culture filtrates were used as the control. All the plates were then incubated at $25^{\circ} \mathrm{C}$ under $16 / 8 \mathrm{~h}$ day/night condition. The inactive J2s were allowed to recover in tap water for $5 \mathrm{~h}$ (Meyer et al., 2004) and then prodded with a needle, and those that did not respond were considered dead. The number of live and inactive nematodes was counted at 24,48 , and $72 \mathrm{~h}$ after the treatments. Each treatment including the control was replicated six times. The mortality of $H$. avenae J2s was calculated as follows (Zhang et al., 2015):

$$
M(\%)=N D S S J / T N S S J \times 100
$$

where $M$ represents mortality, NDSSJ represents the number of dead J2s, and TNSSJ represents the total number of J2s used in each replicate of each treatment.

\section{Optimization of Fermentation Parameters by Single-Factor Experiments}

To investigate the optimum fermentation parameters of T6 culture filtrates for the best nematicidal activity, six key

TABLE 1 | Components of the fermentation media of Trichoderma longibrachiatum T6 used in the study.

\begin{tabular}{|c|c|c|c|}
\hline Code & Media name & Media compounds & Total volume (ml) \\
\hline A & Synthetic medium-1 (SM1) & $\begin{array}{l}\text { [g/L]: }\left(\mathrm{NH}_{4}\right)_{2} \mathrm{SO}_{4}, 2.8 \mathrm{~g} ; \text { Urea, } 0.6 \mathrm{~g} ; \mathrm{KH}_{2} \mathrm{PO}_{4}, 4.0 \mathrm{~g} ; \mathrm{CaCl}_{2} \cdot 2 \mathrm{H}_{2} \mathrm{O} \\
0.6 \mathrm{~g} ; \mathrm{MgSO}_{4}, 0.2 \mathrm{~g} ; \mathrm{FeSO}_{4} \cdot 7 \mathrm{H}_{2} \mathrm{O}, 0.01 \mathrm{~g} ; \mathrm{ZnSO}_{4} \cdot \mathrm{H}_{2} \mathrm{O}, 0.0028 \mathrm{~g} ; \\
\mathrm{CoCl}_{2} \cdot 6 \mathrm{H}_{2} \mathrm{O}, 0.0032 \mathrm{~g} ; \text { Glucose, } 5.0 \mathrm{~g}\end{array}$ & 1,000 \\
\hline$B$ & MM + wheat straw & $\begin{array}{l}\text { [g/L]: Bran, } 6 \mathrm{~g} \text {; Inorganic salt solution, } 4 \mathrm{~g} ; 15 \mathrm{ml}[\%(\mathrm{w} / \mathrm{v}): \\
\left.\mathrm{KH}_{2} \mathrm{PO}_{4}, 1.25 \mathrm{~g} ;\left(\mathrm{NH}_{4}\right)_{2} \mathrm{SO}_{4}, 1.25 \mathrm{~g} ; \mathrm{MgSO}_{4}, 0.3 \mathrm{~g} ; \mathrm{CaCl}_{2}, 0.3 \mathrm{~g}\right]\end{array}$ & 1,000 \\
\hline C & Czapek's Dox liquid medium (CDLM) & $\begin{array}{l}{[\%(\mathrm{w} / \mathrm{v})] \text { : Sucrose, } 3 \% ; \mathrm{NaNO}_{3}, 0.3 \% ; \mathrm{KCl}, 0.05 \% ; \mathrm{MgSO}_{4}} \\
0.05 \% ; \mathrm{KH}_{2} \mathrm{PO}_{4}, 0.1 \% ; \mathrm{FeSO}_{4}, 0.001 \%\end{array}$ & 1,000 \\
\hline D & Synthetic medium-2 (SM2) & [g/L]: Fresh potato, 200 g; Mannitol, 40 g; Peptone, $6 \mathrm{~g}$ & 1,000 \\
\hline$E$ & MM + Wheat bran-1 & $\begin{array}{l}\text { [g/L]: Wheat bran, } 7 \mathrm{~g} \text {; Salt solution, } 3 \mathrm{ml}\left[\%(\mathrm{w} / \mathrm{v}): \mathrm{NH}_{4} \mathrm{NO}_{3}, 0.5 \% \text {; }\right. \\
\left.\mathrm{KH}_{2} \mathrm{PO}_{4}, 0.2 \% ; \mathrm{NaCl}, 0.1 \% ; \mathrm{MgSO}_{4} \cdot 7 \mathrm{H}_{2} \mathrm{O}, 0.1 \%\right]\end{array}$ & 1,000 \\
\hline $\mathrm{F}$ & Potato dextrose broth (PDB) & [g/L]: Fresh potato, $200 \mathrm{~g}$; Dextrose, $15 \mathrm{~g}$ & 1,000 \\
\hline G & MM + Wheat bran-2 & $\begin{array}{l}\text { [g/L]: Wheat bran, } 25 \mathrm{~g} ; \mathrm{KH}_{2} \mathrm{PO}_{4}, 1 \mathrm{~g} ; \mathrm{K}_{2} \mathrm{HPO}_{4}, 1.5 \mathrm{~g} \\
\mathrm{MgSO}_{4} \cdot 7 \mathrm{H}_{2} \mathrm{O}, 2 \mathrm{~g} ; \mathrm{FeSO}_{4} \cdot 7 \mathrm{H}_{2} \mathrm{O}, 0.1 \mathrm{~g}\end{array}$ & 1,000 \\
\hline $\mathrm{H}$ & $\mathrm{MM}+$ Corn flour & $\begin{array}{l}\text { [g/L]: Corn flour, } 25 \mathrm{~g} ; \mathrm{KH}_{2} \mathrm{PO}_{4}, 1 \mathrm{~g} ; \mathrm{K}_{2} \mathrm{HPO}_{4}, 1.5 \mathrm{~g} \\
\mathrm{MgSO}_{4} \cdot 7 \mathrm{H}_{2} \mathrm{O}, 2 \mathrm{~g} ; \mathrm{FeSO}_{4} \cdot 7 \mathrm{H}_{2} \mathrm{O}, 0.1 \mathrm{~g}\end{array}$ & 1,000 \\
\hline I & MM + Chitinase & $\mathrm{NaCl}, 10 \mathrm{mM} ; \mathrm{KCl}, 10 \mathrm{mM}$; $\mathrm{CaCl}_{2}, 3 \mathrm{mM}$; [\% w/v]: 0.4\% chitin & 1,000 \\
\hline$J$ & MM + Chitinase + Proteinase & $\begin{array}{l}\mathrm{NaCl}, 10 \mathrm{mM} \text {; } \mathrm{KCl}, 10 \mathrm{mM} \text {; } \mathrm{CaCl}_{2}, 3 \mathrm{mM} \text {; [\% w/v]: Vitellin, } 0.2 \% \text {; } \\
\text { Chitin, } 0.2 \% \text {; Chicken egg yolk, 0.7\%; Asparagine, } 0.2 \% \text {; } \mathrm{NaNO}_{3} \text {, } \\
0.2 \% \text {; Glucose, } 2 \%\end{array}$ & 1,000 \\
\hline
\end{tabular}


fermentation parameters were studied individually by the quasioptimum protocol (single-variable approach) to evaluate the effect of each fermentation conditions on the nematicidal activity of T6 culture filtrates, including (i) $\mathrm{pH}$, (ii) incubation temperature, (iii) inoculation volume, (iv) liquid media volume, (v) rotating speed, and (vi) incubation day. Two controls were set: the J2s were treated with sterilized water as negative control, and the J2s were treated with the fermentation media without T6 strain as positive control.

The parameters were initially set as follows: $\mathrm{pH} 6.0$; incubation temperature, $25^{\circ} \mathrm{C}$; inoculation volume, $1 \mathrm{ml}$; incubation time, 5 days; fermentation volume, $60 \mathrm{ml}$; and rotating speed, $150 \mathrm{rpm}$. Then, the six parameters of the fermentation media were varied individually from their initial level. Each treatment was replicated six times, and the mean percentages of J2s mortality were calculated to assay the nematicidal activity of T6 culture filtrates. The fermentation media $\mathrm{pH}$ was adjusted to 4.0, 5.0, 6.0, 7.0, 8.0, and 9.0 with appropriate amounts of $\mathrm{HCl}$ or $\mathrm{KOH}$ and agar prior to sterilization. The incubation temperature was adjusted to 20 , $25,28,30$, and $35^{\circ} \mathrm{C}$. The volume of inoculation was set at $0.5,1.0$, $1.5,2.0,2.5$, and $3.0 \mathrm{ml}$ in a $150 \mathrm{ml}$ flask. The liquid media volume was set at $30,40,50,60,70$, and $80 \mathrm{ml}$. The rotating speed was set at $100,120,140,160,180$, and $200 \mathrm{rpm}$. The incubation day was adjusted from 4 to 9 days with a 1-day internal. The nematicidal activity of T6 strain culture filtrates was assessed by extracting samples from each fermentation condition.

\section{Screening Significant Fermentation Parameters by the Plackett-Burman Design}

The Plackett-Burman design was used to screen the fermentation parameters that significantly influence the nematicidal activity of T6 culture filtrates under different fermentation conditions. The independent parameters used in the Plackett-Burman design were (i) $\mathrm{pH}$ (4.0 and 9.0), (ii) incubation temperature $\left(20^{\circ} \mathrm{C}\right.$ and $35^{\circ} \mathrm{C}$ ), (iii) inoculation volume $(0.5 \mathrm{ml}$ and $3 \mathrm{ml})$, (iv) liquid media volume $(30 \mathrm{ml}$ and $80 \mathrm{ml})$, (v) rotating speed $(100 \mathrm{rpm}$ and $200 \mathrm{rpm}$ ), and (vi) incubation day (4 days and 9 days). They were experimentally screened with 12 trials at two levels: -1 for low level and +1 for high level. The actual high and low values of each parameter with whole randomized experimental design are presented in Table 2. Each trail was conducted with six replicates and the mean mortality at $72 \mathrm{~h}$ was taken as the response. Minitab 17 statistical software (Minitab Inc., United States) was used as a tool for screening in the Plackett-Burman design. The firstorder polynomial model was adopted to evaluate the effect of each independent variable to the response:

$$
Y=\beta_{0}+\Sigma \beta_{i} \chi_{i}
$$

where $Y$ is the response of mortality (\%), $\beta_{0}$ is the model intercept, $\beta_{i}$ is the linear coefficient, and $\chi_{i}$ is the level of the independent fermentation parameters ( $i=\mathrm{i}$, ii, iii, iv, v, and vi).

\section{Optimizing Significant Fermentation Parameters by RSM}

From the data sets obtained from the above Plackett-Burman design experiments, the Box-Behnken method (Design Expert software, version 10.7, Stat-Ease Inc., United States) was performed to identify fermentation parameters that have a significant effect on the bio-control potential of T6 culture filtrates and to evaluate the optimum level and interactive effects of the significant parameters influencing the nematicidal activity of T6 culture filtrates. These significant parameters were considered as the significant independent variables and used in the RSM to further optimize each of these significant parameters with two levels, high and low, denoted by $(+1)$ and $(-1)$, respectively, for the enhanced nematicidal activity of T6 culture filtrates (Table 3 ). The proper levels of each variable were determined based on the method for the single-factor experiment for the mortality of the J2s caused by T6 culture filtrates. A polynomial quadratic equation was adopted to evaluate the effect of each independent variable $(i$ and $j$ ) to the response:

TABLE 2 | PBD matrix for screening of independent variables with actual values affecting the nematicidal activity (mortality) of Trichoderma longibrachiatum T6 culture filtrates.

\begin{tabular}{|c|c|c|c|c|c|c|c|c|}
\hline \multirow[t]{2}{*}{ Run number } & \multirow[t]{2}{*}{ Initial pH } & \multirow{2}{*}{$\begin{array}{c}\text { Incubation } \\
\text { temperature }\left({ }^{\circ} \mathrm{C}\right)\end{array}$} & \multirow{2}{*}{$\begin{array}{l}\text { Inoculation } \\
\text { volume (ml) }\end{array}$} & \multirow{2}{*}{$\begin{array}{c}\text { Liquid } \\
\text { volume (ml) }\end{array}$} & \multirow{2}{*}{$\begin{array}{c}\text { Rotating } \\
\text { speed (rpm) }\end{array}$} & \multirow{2}{*}{$\begin{array}{l}\text { Incubation } \\
\text { day (days) }\end{array}$} & \multicolumn{2}{|c|}{ Y: Mortality (\%) } \\
\hline & & & & & & & Actual & Predicted \\
\hline 1 & 4 & 35 & 3 & 80 & 100 & 9 & 72.57 & 72.53 \\
\hline 2 & 9 & 35 & 3 & 30 & 200 & 9 & 69.02 & 69.14 \\
\hline 3 & 4 & 35 & 3 & 30 & 200 & 4 & 70.41 & 70.15 \\
\hline 4 & 9 & 35 & 0.5 & 80 & 100 & 4 & 69.32 & 69.56 \\
\hline 5 & 4 & 35 & 0.5 & 30 & 100 & 9 & 73.65 & 73.82 \\
\hline 6 & 4 & 20 & 0.5 & 30 & 100 & 4 & 73.08 & 72.43 \\
\hline 7 & 9 & 35 & 0.5 & 80 & 200 & 4 & 70.43 & 70.19 \\
\hline 8 & 4 & 20 & 0.5 & 80 & 200 & 9 & 75.22 & 76.08 \\
\hline 9 & 9 & 20 & 0.5 & 30 & 200 & 9 & 72.45 & 72.06 \\
\hline 10 & 9 & 20 & 3 & 30 & 100 & 4 & 66.12 & 67.12 \\
\hline 11 & 9 & 20 & 3 & 80 & 100 & 9 & 70.87 & 70.14 \\
\hline 12 & 4 & 20 & 3 & 80 & 200 & 4 & 71.87 & 71.78 \\
\hline
\end{tabular}


TABLE 3 | Values of independent variables and the levels used in central composite design for optimization of expression.

\begin{tabular}{lccc}
\hline Code & Factors & \multicolumn{2}{c}{ Levels } \\
\cline { 3 - 4 } & & $-\mathbf{1}$ & $\mathbf{1}$ \\
\hline A & Initial pH value & 4 & 9 \\
B & Inoculation volume $(\mathrm{ml})$ & 0.5 & 3 \\
C & Incubation day (days) & 4 & 9 \\
\hline
\end{tabular}

$$
Y=\beta_{0}+\Sigma \beta_{i} \chi_{i}+\Sigma \beta_{i i} \chi_{i}^{2}+\Sigma \beta_{i j} \chi_{i} \chi_{j}
$$

where $Y$ is the measured response associated with each parameter by level combination: $\beta_{0}$ is an intercept; $\beta_{i}$ is regression coefficients computed from the observed experimental values of $Y$; and $X_{i}$ is the coded levels of independent variables. The terms $X_{i} X_{j}$ and $X^{2}{ }_{i}$ represent the interaction and quadratic terms, respectively. $\beta_{i j}$ is the quadratic coefficient and $\beta_{j}$ is the $i j$ interaction coefficient.

The predicted mortalities were verified experimentally as in "Preparation of T. longibrachiatum T6 culture filtrates" and "The nematicidal activity assay of T6 culture filtrates" with 12 replicates under each parameter combination. Statistical significance of the obtained equation was assessed by an F-test and the analysis of variance (ANOVA) for response surface quadratic model.

\section{Greenhouse Bio-control Experiment}

The $H$. avenae susceptible wheat cultivar of Yongliang 4 was used to identify the effectiveness of T6 culture filtrates to control $H$. avenae in greenhouse experiment. The wheat seeds were sterilized and planted according to the method described by Zhang et al. (2017). Each pot had 10 seedlings, and they were irrigated with sterile distilled water every 2 days after seedling emergence. The experiment was arranged using a completely randomized design. When the seedlings reached $8 \mathrm{~cm}$ in height, each pot was inoculated with $1600 \pm 100 \mathrm{~J} 2 \mathrm{~s}$ of $H$. avenae. Ten days after the inoculation, the seedlings were inoculated with $10 \mathrm{ml}$ of T6 culture filtrates. The wheat seedlings inoculated with the same number of $\mathrm{J} 2 \mathrm{~s}$ and $10 \mathrm{ml}$ of sterilized distilled water but without T6 culture filtrates were considered as the negative control, and seedlings inoculated with $\mathrm{J} 2 \mathrm{~s}$ and $10 \mathrm{ml}$ of liquid fermentation medium were used as positive control. The wheat seedlings inoculated with the same number of J2s and $2 \mathrm{ml}$ of $1.8 \%$ abamectin emulsifiable concentrate (EC) (2000 dilutions) were also included to compare with the T6 culture filtrate treatment. The inoculated seedlings were grown with supplemental day/night lighting of $16 / 8 \mathrm{~h}$ at $25^{\circ} \mathrm{C}$, and relative humidity of $65 \%$. Seventy days after seedling inoculation, the parameters of number of juveniles in soil and bio-control efficacy were recorded and determined.

\section{Statistical Analysis}

Minitab Statistical Software (version 17, Minitab Inc., United States) was used to screen the significant parameters affecting the nematicidal activity. The response surfaces of the variables inside the experimental domain were analyzed using Design Expert software (Version 10.7, Stat-Ease Inc., United States). The quality of the fit to the polynomial model equation was expressed by the coefficient of determination $R^{2}$, and the significances of the regression coefficient were checked by $F$-test and $p$-value. The values of "Prob $>F$ " less than 0.05 indicate the significant model terms, while values greater than 0.10 indicate that the model terms are not significant. A large number of insignificant model terms could be improved by model reduction. The adequacy of the regression model was estimated by drawing the diagnostic plots. The $R^{2}$ coefficient was calculated as the indicator of the model fitting. The model would be stronger and the prediction of the response would be better if the $R^{2}$ coefficient approaches 1 .

Data from experiments were subjected to ANOVA and expressed as means of standard errors (SE) of 6 or 12 replicates. One-way ANOVA was performed to determine the treatment effect using SPSS Version 16.0 (SPSS Inc., Chicago, IL). Treatment effects were determined using Duncan's multiple range test and the significances were expressed at $p<0.05$.

\section{RESULTS}

\section{Effect of Fermentation Media on the Nematicidal Activity of T6 Culture Filtrates}

Compared with the control, the T6 cultural filtrates from 10 different fermentation media showed different degrees of nematicidal activity against $H$. avenae J2s. Among the fermentation media (Table 1), the T6 cultural filtrates from the MM + wheat bran-2 (G), MM + chitinase medium (I), and $\mathrm{MM}+$ chitinase + proteinase $(\mathrm{J})$ had a higher nematicidal activity with mortalities of $91.44,89.04$, and $90.38 \%$, respectively, after $72 \mathrm{~h}$ incubation. The T6 cultural filtrates from other four media, synthetic medium-1 (A), Czapek's Dox liquid medium (C), $\mathrm{MM}+$ wheat bran-1 (E), and potato dextrose broth (F), produced mortalities from 80.06 to $88.75 \%$ after $72 \mathrm{~h}$ incubation. The T6 cultural filtrates from the MM + corn flour medium (H) exhibited the lowest mortality of only $62.94 \%$ after $72 \mathrm{~h}$ incubation. Thus, the MM + wheat bran-2 $(\mathrm{G})$ was considered as the most effective fermentation medium for the T6 strain against H. avenae J2s (Table 4).

\section{Key Fermentation Parameters for Maximizing the Nematicidal Activity of T6 Culture Filtrates}

Six fermentation parameters (initial $\mathrm{pH}$, incubation temperature, inoculation volume, liquid media volume, rotating speed, and incubation day) of the $\mathrm{G}$ medium (MM + wheat bran-2) exhibited a significant effect on the nematicidal activity of T6 culture filtrates (Figure 1). Increasing incubation time from 24 to $72 \mathrm{~h}$ significantly and continuously increased the nematicidal activity. After $72 \mathrm{~h}$ incubation with the $\mathrm{G}$ medium, the highest nematicidal activity was achieved: $89.67 \%$ at initial $\mathrm{pH} 6$ (Figure 1i), $90.67 \%$ at fermentation temperature $28^{\circ} \mathrm{C}$ (Figure 1ii), 91.57\% with inoculation volume $1 \mathrm{ml}$ (Figure 1iii), 
TABLE 4 | Nematicidal activity (mortality) of Trichoderma longibrachiatum T6 culture filtrates against $H$. avenae with 10 different fermentation media.

\begin{tabular}{lccc}
\hline Medium code & \multicolumn{3}{c}{ Time (h) } \\
\cline { 2 - 4 } & \multicolumn{3}{c}{ Mortality (\%) } \\
\cline { 2 - 4 } & \multicolumn{3}{c}{$\mathbf{4}$} \\
\hline A & $24.79 \pm 1.06 \mathrm{e}$ & $54.33 \pm 1.84 \mathrm{e}$ & $80.57 \pm 2.56 \mathrm{~d}$ \\
$\mathrm{~B}$ & $27.10 \pm 1.86 \mathrm{~d}$ & $56.78 \pm 2.33 \mathrm{de}$ & $73.55 \pm 2.78 \mathrm{f}$ \\
C & $33.69 \pm 2.67 \mathrm{bc}$ & $64.22 \pm 3.07 \mathrm{~b}$ & $80.06 \pm 2.88 \mathrm{~d}$ \\
$\mathrm{D}$ & $31.00 \pm 1.98 \mathrm{c}$ & $63.39 \pm 1.78 \mathrm{~b}$ & $79.33 \pm 2.34 \mathrm{e}$ \\
E & $34.14 \pm 2.54 \mathrm{~b}$ & $58.64 \pm 3.03 \mathrm{~d}$ & $88.75 \pm 3.32 \mathrm{~b}$ \\
F & $36.27 \pm 1.46 \mathrm{a}$ & $60.34 \pm 2.36 \mathrm{c}$ & $86.26 \pm 2.88 \mathrm{c}$ \\
G & $31.37 \pm 2.54 \mathrm{c}$ & $68.58 \pm 3.26 \mathrm{a}$ & $91.44 \pm 3.32 \mathrm{a}$ \\
H & $25.80 \pm 1.22 \mathrm{e}$ & $44.18 \pm 2.05 \mathrm{f}$ & $62.94 \pm 3.20 \mathrm{~g}$ \\
I & $28.00 \pm 1.97 \mathrm{~d}$ & $57.98 \pm 2.38 \mathrm{~d}$ & $89.04 \pm 3.10 \mathrm{ab}$ \\
$\mathrm{J}$ & $34.29 \pm 2.05 \mathrm{~b}$ & $65.71 \pm 3.07 \mathrm{~b}$ & $90.38 \pm 2.88 \mathrm{a}$ \\
Control & $7.46 \pm 0.78 \mathrm{f}$ & $9.37 \pm 0.78 \mathrm{~g}$ & $10.67 \pm 1.04 \mathrm{~h}$
\end{tabular}

Data are means \pm standard error of six replicates and those in a column followed by different letters are significantly different at $p<0.05$, based on Duncan's new multiple range test using one-way ANOVA $(n=6)$. The mortality (\%) was determined at 24, 48, and $72 \mathrm{~h}$ after inoculation of the J2s with either T6 fermentation or sterile water (control). The medium code is detailed in the footnote of Table 1.

87.35\% with liquid media volume $60 \mathrm{ml}$ (Figure 1iv), $86.54 \%$ with rotating speed $180 \mathrm{rpm}$ (Figure 1v), and $90.00 \%$ with incubation time 7 days (Figure 1vi).

\section{Contribution of the Fermentation Parameters in the Nematicidal Activity of T6 Culture Filtrates}

The Plackett-Burman design was used to screen the fermentation parameters (used as factors in the design) for their significant contribution to the nematicidal activity of T6 culture filtrates. In Plackett-Burman design experiments, the nematicidal activity (mortality) varied from 66.12 to $75.22 \%$. The mortality of different parameter combinations after $72 \mathrm{~h}$ incubation under the influence of the parameters at high and low levels is shown in Table 2. The highest mortality (75.22\%) was observed in the $12^{\text {th }}$ run with a combination of initial $\mathrm{pH} 4.0$, fermentation temperature, $20^{\circ} \mathrm{C}$; inoculation volume, $0.5 \mathrm{ml}$; incubation day, 9 days; rotating speed, $200 \mathrm{rpm}$; and inoculation volume, $80 \mathrm{ml}$. A high correlation was observed between these predicted mortalities and the experimental mortalities obtained in Table 2 (Figure 2A).

Statistical significance was assessed by an $F$-test and the ANOVA for Plackett-Burman design quadratic model. The first-order model was obtained with experimental results as follows: $Y=73.43-0.6197 \mathrm{i}-0.0468 \mathrm{ii}$ $0.886 \mathrm{iii}+0.0185 \mathrm{iv}+0.00632 \mathrm{v}+0.4183 \mathrm{vi}$, where $Y$ is predicted response and i, ii, iii, iv, v, and vi are the coded values of initial $\mathrm{pH}$, fermentation temperature, inoculation volume, liquid volume, rotating speed, and incubation day, respectively. The regression analysis indicated a significance of the model terms at $p<0.01$ and a high correlation between the observed and predicted values between the independent parameters and the response (Table 5). The coefficient of determined $R^{2}$ and
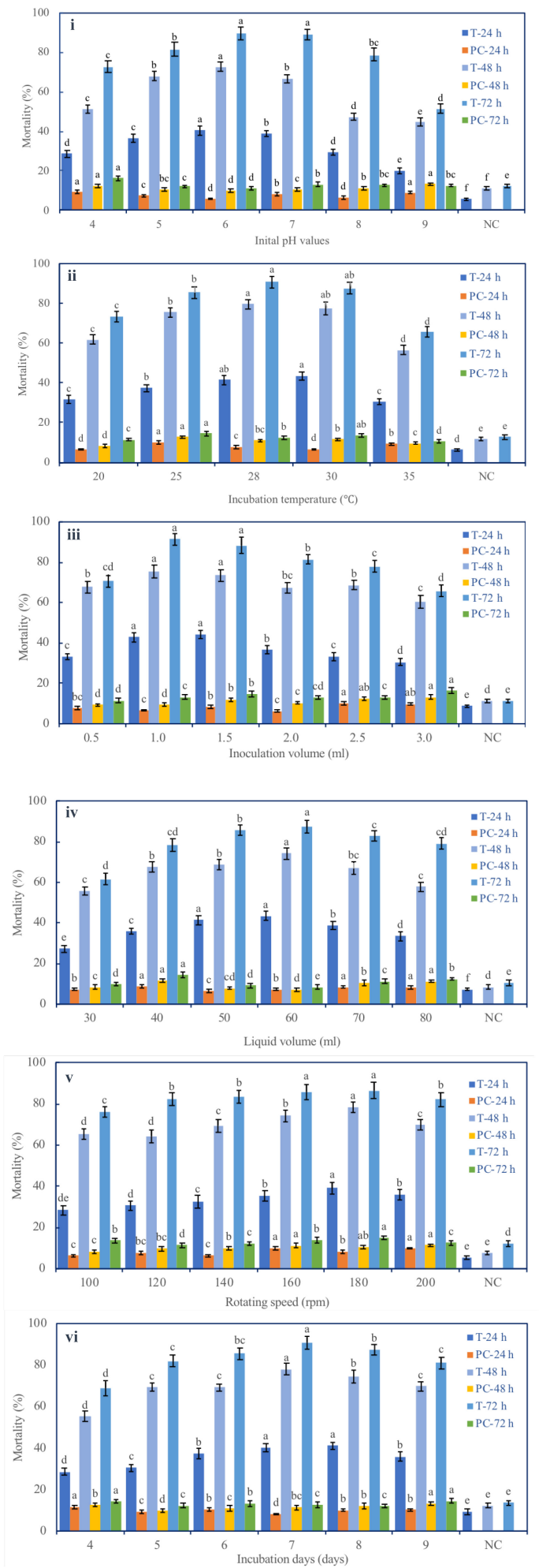

FIGURE 1 | Effect of different fermentation parameters on the nematicidal activity of Trichoderma longibrachiatum T6 culture filtrates against $H$. avenae. The mortalities are shown under the parameters of (i) initial pH, (ii) incubation temperature, (iii) inoculation volume, (iv) liquid volume, (v) rotating speed, and (vi) incubation day. T represents T6 culture filtrate treatment. PC represents (Continued) 


\section{FIGURE 1 | Continued}

the J2s that were treated with the liquid fermentation medium but not with T. longibrachiatum T6 (positive control). NC represents the J2s that were treated with sterilized water (negative control). The keys are T-24 h, T-48 h, and T-72 h for T6 culture filtrate treatments, and PC-24 h, PC-48 h, and $\mathrm{PC}-72 \mathrm{~h}$ for the positive controls at $24 \mathrm{~h}, 48 \mathrm{~h}$, and $72 \mathrm{~h}$ after the treatments, respectively. The data are grouped by the parameter, and there are six groups (i-vi). The statistical analysis was applied in each group on the mortality for each treatment (T-24 h, PC-24 h, T-48 h, PC-48 h, T-72 h, and PC-72 h). Data are means of six replicates \pm standard error. The line bars represent the standard errors of the means. Different letters denote significant difference at $p<0.05$ based on Duncan's new multiple range tests using one-way ANOVA for a range of each fermentation parameter.

adjusted $R^{2}$ were 0.95 and 0.90 , respectively. The initial $\mathrm{pH}$, inoculation volume, and incubation day were predicted to have a significant and substantial influence on the nematicidal activity of T6 culture filtrates among all six fermentation parameters (Figures 2B,C and Table 5).

\section{RSM Analysis of the Significant Parameters}

Based on the single-factor experiments and the Plackett-Burman design experiments above, the initial $\mathrm{pH}$, inoculation volume, and incubation day were selected as the independent variables in the response surface optimization (RSM) at two levels $(-1$ and +1 ) (Table 3).

The optimization of the selected parameters was carried out through 17 experiments with five replications of the central points each experiment (Table 6). The quadratic polynomial model obtained by regression was: $Y=19.33 \mathrm{~A}+18.41 \mathrm{~B}+12.34 \mathrm{C}-5.04 \mathrm{AB}+4.00 \mathrm{AC}-0.35 \mathrm{BC}-$ $1.60 A^{2}-4.91 B^{2}-0.82 C^{2}-25.46$, which was used to calculate the predicted mortality as a function of initial $\mathrm{pH}$ value (A), inoculation volume (B), and incubation day (C).

In order to understand the effect of the independent variables on the dependent variable, the response surface plots of the quadratic polynomial model were generated by varying one of the independent variables within the experimental range while holding other variables constant at the central point. The results of statistical assessment [F-value: 71.93 and $P$ (Prob $>F)<0.0001]$ confirmed the significance of the model terms with regression coefficient constants $R^{2}$ of 0.99 and Pred $R^{2}$ of 0.92 , which are in reasonable agreement with the Adj $R^{2}$ of 0.98. The model terms A, B, C, $\mathrm{A}^{2}, \mathrm{~B}^{2}$, and $\mathrm{C}^{2}$ could be considered as significant terms (Table 7 ). The RSM results showed that initial $\mathrm{pH}$ value (A), inoculation volume (B), and incubation day (C) could adequately describe the response (mortality).

The $2 \mathrm{D}$ contour plots and the $3 \mathrm{D}$ response surface plots further showed that the mortality was mainly determined by different combinations of two parameters, i.e., initial $\mathrm{pH}$ value and incubation day (Figures $\mathbf{3 A}, \mathbf{B}$ ), inoculation volume and incubation day (Figures 4A,B), and initial $\mathrm{pH}$ value and inoculation volume (Figures 5A,B). For the response contour plots (Figures 3A, 4A, 5A), the maximum mortality of $92.05 \%$ was obtained at initial $\mathrm{pH}, 6.06$; inoculation volume, $1.62 \mathrm{ml}$; and incubation day, 7.15 days. Also, the 3D surface contour

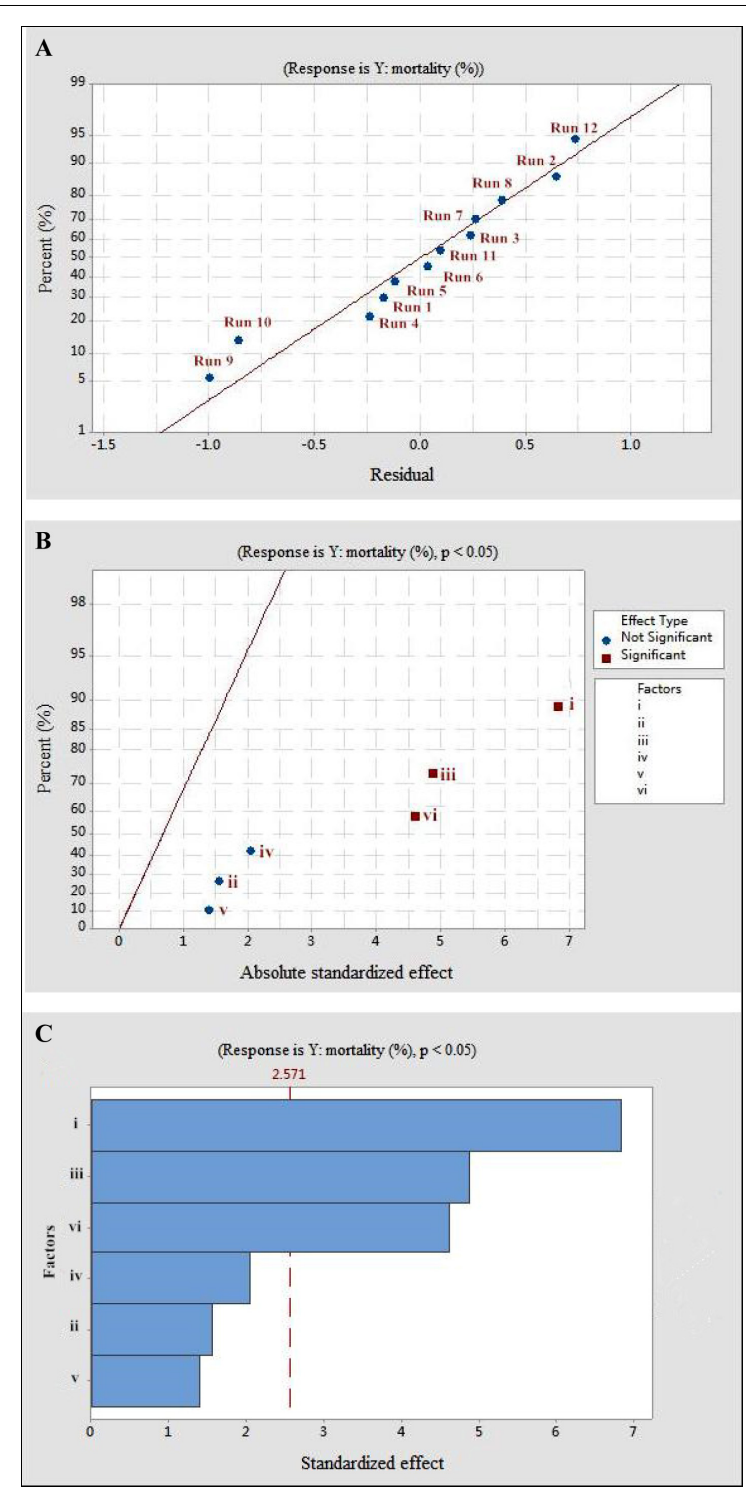

FIGURE 2 | The mortality response to the effects of residuals, absolute standardized effect, and standardized effect on the nematicidal activity of Trichoderma longibrachiatum T6 against $H$. avenae as presented with (A) normal plot, (B) half normal plot, and (C) pareto chart presentation, with (i) initial $\mathrm{pH}$, (ii) incubation temperature, (iii) inoculation volume, (iv) liquid volume, (v) rotating speed, and (vi) incubation day.

plots displayed the predicted mortality of $92.05 \%$ at the twoparameter combinations (Figures 3B, 4B, 5B). Moreover, these two-parameter combinations were found to have synergistic effects on the mortality in comparison to the data in Table 6.

\section{Verification of the Nematicidal Activity of T6 Culture Filtrates From Optimized Fermentation Media}

The nematicidal activity (mortality) of the T6 culture filtrates from the optimized fermentation medium was determined again using the predicted optimal conditions as follows: initial $\mathrm{pH}, 6.06$; 
TABLE 5 | Regression coefficient and analysis of variance for the quadratic model for the nematicidal activity (mortality) of Trichoderma longibrachiatum T6 culture filtrates.

\begin{tabular}{|c|c|c|c|c|c|c|c|}
\hline Term & Effect & Coefficient & Df & Adj SS & Adj MS & $F$-value & $p$-value \\
\hline Model & & & 6 & 61.884 & 10.314 & 16.690 & $0.004^{*}$ \\
\hline Linear & & & 6 & 61.884 & 10.314 & 16.690 & $0.004^{*}$ \\
\hline Constant & & 71.251 & & & & & $0.000^{*}$ \\
\hline i. Initial $\mathrm{pH}$ & -3.098 & -1.549 & 1 & 28.799 & 28.799 & 46.600 & $0.001^{*}$ \\
\hline $\begin{array}{l}\text { ii. Incubation } \\
\text { temperature }\left({ }^{\circ} \mathrm{C}\right)\end{array}$ & -0.702 & -0.351 & 1 & 1.477 & 1.477 & 2.390 & 0.183 \\
\hline $\begin{array}{l}\text { iii. Inoculation } \\
\text { volume (ml) }\end{array}$ & -2.215 & -1.108 & 1 & 14.719 & 14.719 & 23.820 & $0.005^{\star}$ \\
\hline $\begin{array}{l}\text { iv. Liquid volume } \\
\text { (ml) }\end{array}$ & 0.925 & 0.462 & 1 & 2.567 & 2.567 & 4.150 & 0.097 \\
\hline $\begin{array}{l}\text { v. Rotating speed } \\
\text { (rpm) }\end{array}$ & 0.632 & 0.316 & 1 & 1.197 & 1.197 & 1.940 & 0.223 \\
\hline $\begin{array}{l}\text { vi. Incubation day } \\
\text { (days) }\end{array}$ & 2.092 & 1.046 & 1 & 13.125 & 13.125 & 21.240 & $0.006^{*}$ \\
\hline Residual error & & & 5 & 3.09 & 0.618 & & \\
\hline Total & & & 11 & 64.974 & & & \\
\hline
\end{tabular}

$F$ is Fisher's function; probability * $p<0.05$ corresponds to significance.

TABLE 6 | Box-Behnken design with the measured and predicted response of mortality in relation to the three key parameters of $\mathrm{pH}(A)$, inoculation volume $(B)$, and incubation day $(\mathrm{C})$.

\begin{tabular}{lcccccc}
\hline Run number & \multicolumn{3}{c}{ Parameters } & & \multicolumn{2}{c}{ Y: Mortality (\%) } \\
\cline { 2 - 4 } & A & B & C & & Actual & Predicted \\
\hline 1 & 4.00 & 1.75 & 9.00 & & 81.74 & 82.29 \\
2 & 4.00 & 3.00 & 6.50 & & 76.44 & 75.89 \\
3 & 6.50 & 1.75 & 6.50 & 92.33 & 91.34 \\
4 & 6.50 & 1.75 & 6.50 & 92.62 & 91.34 \\
5 & 9.00 & 1.75 & 9.00 & 74.67 & 75.22 \\
6 & 9.00 & 3.00 & 6.50 & 69.37 & 68.82 \\
7 & 6.50 & 1.75 & 6.50 & 90.67 & 91.34 \\
8 & 6.50 & 3.00 & 9.00 & 78.63 & 78.63 \\
9 & 6.50 & 1.75 & 6.50 & 89.53 & 91.34 \\
10 & 9.00 & 1.75 & 4.00 & 70.68 & 70.13 \\
11 & 6.50 & 1.75 & 6.50 & 91.53 & 91.34 \\
12 & 6.50 & 0.50 & 4.00 & 76.20 & 76.20 \\
13 & 4.00 & 0.50 & 6.50 & 78.00 & 78.55 \\
14 & 6.50 & 3.00 & 4.00 & 74.64 & 75.73 \\
15 & 6.50 & 0.50 & 9.00 & 84.56 & 83.47 \\
16 & 9.00 & 0.50 & 6.50 & 70.93 & 71.47 \\
17 & 4.00 & 1.75 & 4.00 & 77.76 & 77.21 \\
\hline & & & & &
\end{tabular}

inoculation volume, $1.62 \mathrm{ml}$; and incubation time, 7.15 days. The results indicated that the nematicidal activity of the T6 culture filtrates was significantly increased (Table 8). The mortality was $92.42 \%$ at $72 \mathrm{~h}$ after treatment, significantly higher than those of positive and negative controls (Table 8) and close to the predicted mortality of $92.05 \%$. This demonstrated that the response quadratic polynomial model could adequately reflect the expected optimization.

In addition, the mortality of the T6 culture filtrates from the optimized fermentation medium was significantly different
TABLE 7 | Analysis of variance (ANOVA) for response surface quadratic model for the nematicidal activity of Trichoderma longibrachiatum T6 culture filtrates.

\begin{tabular}{lccccc}
\hline Source & $\begin{array}{c}\text { Sum of } \\
\text { squares }\end{array}$ & df & $\begin{array}{c}\text { Mean } \\
\text { square }\end{array}$ & F-value & p-value \\
\hline Model & 1032.59 & 9 & 114.73 & 71.93 & $<0.0001^{*}$ \\
A. pH & 100.04 & 1 & 100.04 & 62.72 & $<0.0001^{*}$ \\
B. Inoculation volume & 14.07 & 1 & 14.07 & 8.82 & $0.0208^{*}$ \\
C. Incubation day & 51.61 & 1 & 51.61 & 32.36 & $0.0007^{*}$ \\
AB & 0.000 & 1 & 0.000 & 0.000 & 1.0000 \\
AC & $2.500 \mathrm{E}-005$ & 1 & $2.500 \mathrm{E}-005$ & $1.567 \mathrm{E}-005$ & 0.9970 \\
BC & 4.77 & 1 & 4.77 & 2.99 & 0.1272 \\
A $^{2}$ & 418.78 & 1 & 418.78 & 262.57 & $<0.0001^{*}$ \\
B $^{2}$ & 248.22 & 1 & 248.22 & 155.63 & $<0.0001^{*}$ \\
C $^{2}$ & 111.70 & 1 & 111.70 & 70.03 & $<0.0001^{*}$ \\
Residual & 11.16 & 7 & 1.59 & & \\
Lack of fit & 4.79 & 3 & 1.60 & 1.00 & 0.4789 \\
Pure error & 6.38 & 4 & 1.59 & & \\
Cor total & 1043.76 & 16 & & & \\
\hline Fis Fisher & & & & & \\
\hline
\end{tabular}

Fis Fisher's function; probability ${ }^{*} p<0.05$ corresponds to significance.

from that of the T6 culture filtrates from the MM + wheat bran-2 (G) medium. The nematicidal activity was increased approximately by as much as $1.07 \%$ compared with that before optimization (Table 8).

\section{Bio-control Efficacy in Greenhouse}

The number of $H$. avenae J2s in soil was significantly decreased after the application of $\mathrm{T} 6$ fermentation and abamectin at 70 days after wheat seeds sowing in comparison to the two controls. Meanwhile, the treatments with T6 culture filtrates exhibited higher bio-control efficacy than the abamectin treatment in the greenhouse experiments. The bio-control efficacy of T6 culture filtrates was $83.88 \%$ at the $70^{\text {th }}$ day after wheat seeds sowing, whereas the bio-control efficacy of abamectin was $77.15 \%$ in comparison to wheat seedlings treated with sterilized water (Table 9).

\section{DISCUSSION}

In the present study, the $\mathrm{MM}+$ wheat bran-2 (wheat bran, $25 \mathrm{~g}$; $\mathrm{KH}_{2} \mathrm{PO}_{4}, 1 \mathrm{~g} ; \mathrm{K}_{2} \mathrm{HPO}_{4}, 1.5 \mathrm{~g} ; \mathrm{MgSO}_{4} \cdot 7 \mathrm{H}_{2} \mathrm{O}, 2 \mathrm{~g} ; \mathrm{FeSO}_{4} \cdot 7 \mathrm{H}_{2} \mathrm{O}$, $0.1 \mathrm{~g}$ ) was identified as the most effective fermentation medium for the high nematicidal activity of the T6 culture filtrates among 10 fermentation media tested. To the best of our knowledge, this is the first report suggesting that $M M+$ wheat bran-2 medium could increase the nematicidal activity of T6 culture filtrates against $H$. avenae J2s. This is consistent with the previous study of the fermentation medium and fermentation parameters in enhancing the bio-control ability of T. viride YC-108 mutant strain (Yan et al., 2012; Yang et al., 2016). Yan et al. (2012) reported that wheat bran, avicel, and soya-bean cake powder, nitrogen source, and soybean meal could promote and increase the cellulase production from the strain of $T$. reesei $\mathrm{YC}-108$. In addition, Wang et al. (2014) revealed that the components of $\mathrm{K}_{2} \mathrm{HPO}_{4}$, beef extract, 


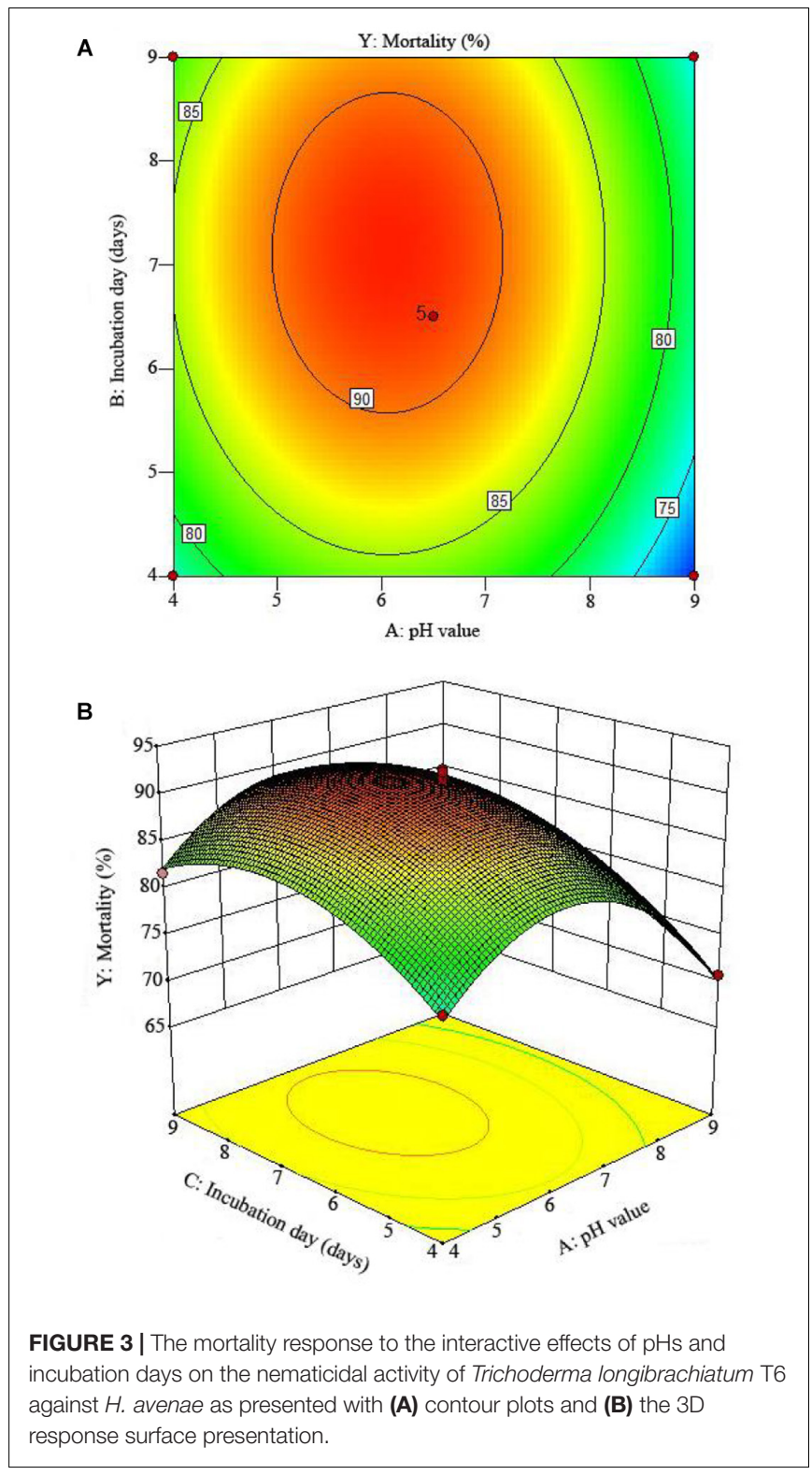

beef peptone, and glucose in a liquid fermentation medium improved the nematicidal activity of the nematode pathogenic strain Xenorhabdus nematophila HB301. It was found that the optimal enzymatic activity of the strain T. harzianum F470 was obtained with the fermentation medium of crude state and at the cultural conditions of temperature $40^{\circ} \mathrm{C}$ and pH 5.5 (Wiater and Szczodrak, 2001). Sharma et al. (2014) found that the mortality of $M$. incognita J2s was increased to $100 \%$ if the nematode pathogenic strain P. lilacinus 6029 was fermented on the medium of Karanja cake than the Czapeck-Dox filtrate under the fermentation parameters of a lower $\mathrm{pH}$ and 15 days' incubation time. It was also found that the fermentation parameters of incubation time, initial $\mathrm{pH}$, and temperature were the most important factors for biocontrol of root knot nematodes by $P$. lilacinus production (Yu et al., 2015).

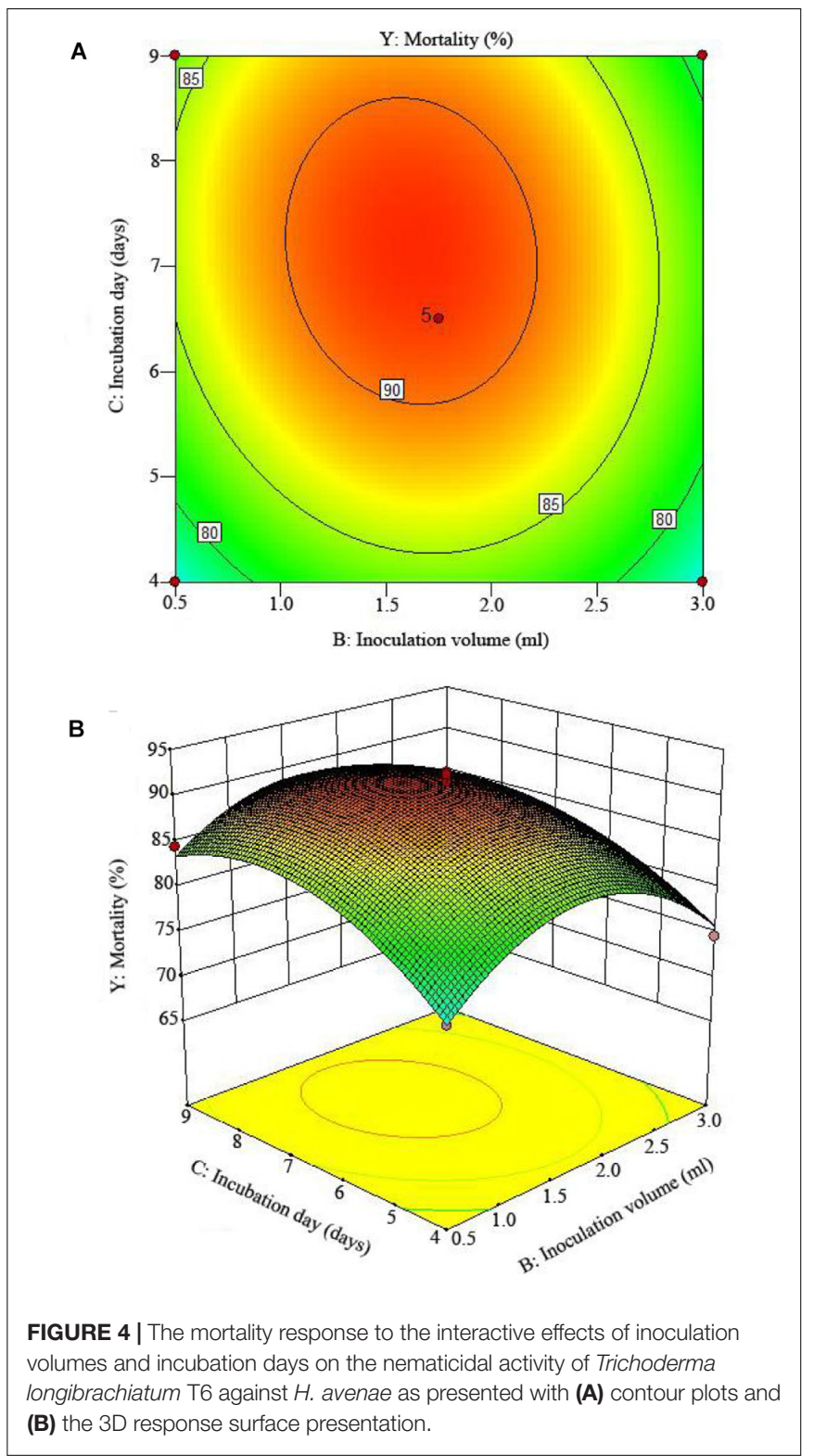

Based on single-factor experiments and the Plackett-Burman design experiments, the optimal fermentation parameters of the $\mathrm{MM}+$ wheat bran-2 medium were an initial $\mathrm{pH}$ of 6 , fermentation temperature at $28^{\circ} \mathrm{C}$, rotating speeds at $180 \mathrm{rpm}$, fermentation media volume of $60 \mathrm{ml}$, inoculum volume of $1 \mathrm{ml}$, and incubation for 7 days. They made a significant effect on increasing the nematicidal activity of T6 culture filtrates against $H$. avenae J2s. Li et al. (2016) found, using the PlackettBurman design, that cornmeal, glycerol, and initial $\mathrm{pH}$ were the most significant parameters for enhancing the production of chlamydospores of T. harzianum SH2303 in liquid fermentation. Through Plackett-Burman screening experiments, Yang et al. (2016) reported that three fermentation parameters such as initial $\mathrm{pH}$, concentration of sucrose, and $\mathrm{MgSO}_{4} \cdot 7 \mathrm{H}_{2} \mathrm{O}$ in a broth had significant effects on the nematicidal activity of Simplicillium chinense strain Snef5 against $M$. incognita J2s. By 

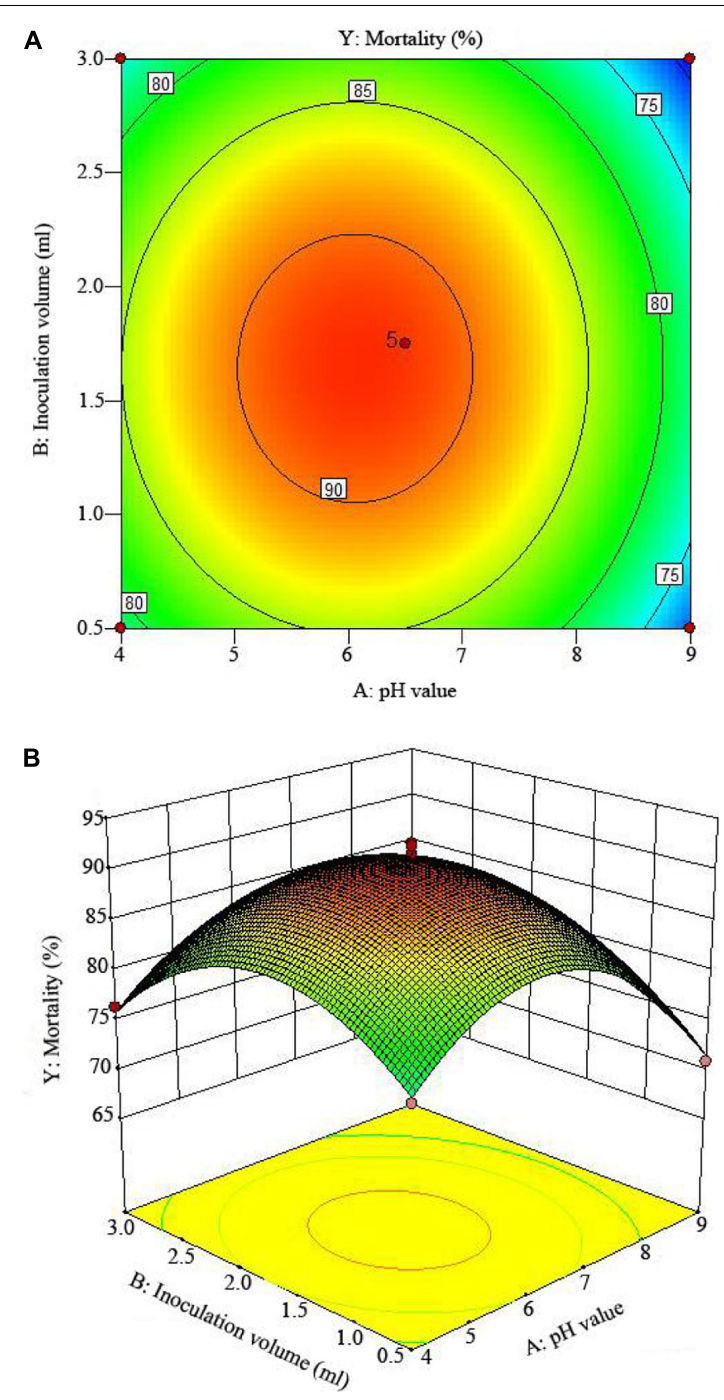

FIGURE 5 | The mortality response to the interactive effects of $\mathrm{pHs}$ and inoculation volumes on the nematicidal activity of Trichoderma longibrachiatum T6 against $H$. avenae as presented with (A) contour plots and (B) the 3D response surface presentation.

further study using the Box-Behnken design and RSM, Yang et al. (2016) redefined the optimal conditions for the strain S. chinense Snef5 fermentation as 6.74 initial pH, 4.19\% sucrose, and $0.04 \% \mathrm{MgSO}_{4} \cdot 7 \mathrm{H}_{2} \mathrm{O}$ in the medium, and further enhanced the nematicidal activity of the strain Snef5. Similarly, in the current study, the optimal fermentation parameters for the nematicidal activity of T6 culture filtrates were redefined as initial $\mathrm{pH}, 6.06$; inoculum quantity, $1.62 \mathrm{ml}$; and incubation time, 7.15 days. Under such optimized condition, the nematicidal activity and bio-control efficacy of T6 culture filtrates was significantly increased. The mortality results of the verification experiments under these conditions correlated well with the predicted mortalities with good Adj $R^{2}$ and $R^{2}$-values.

Our study demonstrated that RSM is a valuable tool to optimize the fermentation parameters (Trupkin et al., 2003;
TABLE 8 | Verification of the nematicidal activity of Trichoderma Iongibrachiatum T6 culture filtrates against $H$. avenae at 24,48 , and $72 \mathrm{~h}$ after incubation under optimal conditions.

\begin{tabular}{lccc}
\hline Treatments & \multicolumn{3}{c}{ Time (h) } \\
\cline { 2 - 4 } & $\mathbf{2 4}$ & $\mathbf{4 8}$ & $\mathbf{7 2}$ \\
\hline & \multicolumn{3}{c}{ Mortality (\%) } \\
\hline T6 culture filtrates & $48.34 \pm 2.22 \mathrm{a}$ & $78.43 \pm 2.53 \mathrm{a}$ & $92.42 \pm 3.34 \mathrm{a}$ \\
MM + Wheat bran-2 & $31.37 \pm 2.54 \mathrm{~b}$ & $68.58 \pm 3.26 \mathrm{~b}$ & $91.44 \pm 3.32 \mathrm{~b}$ \\
Positive control & $7.05 \pm 1.38 \mathrm{c}$ & $13.45 \pm 1.21 \mathrm{c}$ & $14.21 \pm 1.37 \mathrm{c}$ \\
Negative control & $8.58 \pm 0.89 \mathrm{c}$ & $10.07 \pm 1.04 \mathrm{c}$ & $13.28 \pm 1.29 \mathrm{c}$
\end{tabular}

Data are means of 12 replicates \pm standard error. Values in columns followed by different letters are significantly different at $p<0.05$ based on Duncan's new multiple range test using one-way ANOVA $(n=12)$. Negative control represents the J2s that were treated with sterilized water, whereas the positive control represents the J2s that were treated with the fermentation medium without T. Iongibrachiatum T6.

TABLE 9 | Verification of the bio-control activity of Trichoderma longibrachiatum T6 culture filtrates against $H$. avenae in greenhouse experiments at the 70 th day after wheat seeds sowing.

\begin{tabular}{lcc}
\hline Treatments & $\begin{array}{c}\text { Number of juveniles in } \\
\text { soil (per } \mathbf{2 0 0} \mathbf{g} \text { of soil) }\end{array}$ & $\begin{array}{c}\text { Bio-control } \\
\text { efficacy (\%) }\end{array}$ \\
\hline T6 culture filtrates & $74.51 \pm 3.24 \mathrm{c}$ & $83.88 \pm 2.83 \mathrm{a}$ \\
Abamectin & $105.64 \pm 6.75 \mathrm{~b}$ & $77.15 \pm 2.94 \mathrm{~b}$ \\
Positive control & $452.83 \pm 23.11 \mathrm{a}$ & $2.05 \pm 0.21 \mathrm{c}$ \\
Negative control & $462.32 \pm 25.44 \mathrm{a}$ & - \\
\hline
\end{tabular}

Data are means of 12 replicates \pm standard error. Values in columns followed by different letters are significantly different at $p<0.05$ based on Duncan's new multiple range test using one-way ANOVA $(n=12)$. Negative control represents the wheat seedlings that were treated with sterilized water, whereas the positive control represents the seedlings that were treated with the liquid fermentation medium but not with T6 culture filtrates.

Li et al., 2007) due to its advantages of short test cycle, high accuracy, and low test frequency. The differences in the nematicidal activity between our study and previous studies may be due to different strains and their metabolites under different fermentation conditions. The outcome of our work provides a promising reference for future development of more effective and practical bio-nematicide fermentation processes (Ambat and Ayyanna, 2001). Despite the promising results achieved in this study, some issues like the active ingredient on the activity of T6 culture filtrates against $H$. avenae $\mathrm{J} 2 \mathrm{~s}$ need further investigation.

\section{CONCLUSION}

The present study has highlighted the design, analysis, and optimization of the fermentation parameters of the beneficial fungus T. longibrachiatum T6 (T6) for its nematicidal activity and bio-control efficacy enhancement. To the best of our knowledge, the present work is the first report on the application of the Plackett-Burman design and RSM to screen and optimize the fermentation parameters on the bio-control potential 
of $T$. longibrachiatum against $H$. avenae in the surface and submerged fermentation techniques. Our results indicate that statistical analysis using the Plackett-Burman design and RSM is a valuable approach for studying and optimizing the combined effects of fermentation parameters of the beneficial fungi. The model obtained by the Plackett-Burman design and RSM analysis has better precision and reliability in maximizing the nematicidal activity of T6 culture filtrates compared with that before optimization. The model will help to provide a more effective and practical bio-nematicide fermentation process for the development of some novel commercial bio-control agents in the future.

\section{DATA AVAILABILITY STATEMENT}

All datasets presented in this study are included in the article/ supplementary material.

\section{AUTHOR CONTRIBUTIONS}

SZ and YG conceived and designed the experiments with the help of BX. SZ performed most of the optimization of the

\section{REFERENCES}

Ambat, P., and Ayyanna, C. (2001). Optimizing medium constituents and fermentation conditions for citric acid production from palmyra jaggery using response surface methods. J. Microbiol. Biotechnol. 17, 331-335.

Araujo, P. W., and Brereton, R. G. (1996). Experimental design II. optimization. TrAC Trends Anal. Chem. 15, 63-70. doi: 10.1016/0165-9936(96)80762-x

Baklawa, M., Björn, N., and Massoud, S. (2017). Influence of temperature and storage conditions on the hatching behavior of cereal cyst nematodes (Heterodera avenae Wollenweber) from Egypt. J. Plant Dis. Prot. 124, 213-222. doi: 10.1007/s41348-016-0060-x

Baş, D., and Boyaci, I. H. (2007). Modeling and optimization I: usability of response surface methodology. J. Food Eng. 78, 836-845. doi: 10.1016/j.jfoodeng.2005. 11.024

Cui, F. J., Li, Y., Xu, Z. H., Xu, H. Y., Sun, K., and Tao, W. Y. (2006). Optimization of the medium composition for production of mycelial biomass and exopolymer by Grifola frondosa GF9801 using response surface methodology. Bioresource Technol. 97, 1209-1216. doi: 10.1016/j.biortech.2005.05.005

El-Naggar, N. A., El-Shweihy, N. M., and El-Ewasy, S. M. (2016). Identification and statistical optimization of fermentation conditions for a newly isolated extracellular cholesterol oxidase-producing Streptomyces cavourensis strain NEAE-42. BMC Microbiol. 16:217. doi: 10.1186/s12866-016-0830-4

Harman, G. E., Howell, C. R., Viterbo, A., Chet, I., and Lorito, M. (2004). Trichoderma species-opportunistic: avirulent plant symbionts. Nat. Rev. Microbiol. 2, 43-56. doi: 10.1038/nrmicro797

Huang, W. K., Sun, J. H., Cui, J. K., Wang, G. F., Kong, L. A., Peng, H., et al. (2014). Efficacy evaluation of fungus Syncephalastrum racemosum and nematicide abamectin against the root-knot nematode Meloidogyne incognita on cucumber. PLoS One 9:e89717. doi: 10.1371/journal.pone.0089717

Jatala, P. (1986). Biological control of plant parasitic nematodes. Annu. Rev. Phytopathol. 24, 453-489.

Jones, J. T., Haegeman, A., Danchin, E. G. J., Gaur, H. S., Helder, J., Jones, M. G. K., et al. (2013). Top 10 plant-parasitic nematodes in molecular plant pathology. Mol. Plant Pathol. 14, 946-961. doi: 10.1111/mpp.12057

Kerry, B. R. (2001). "Exploitation of the nematophagous fungus Verticillium chlamydosporium goddard for the biological control of root-knot nematodes (Meloidogyne spp.)," in Fungi as Biocontrol Agents, eds T. M. Butt, C. Jackson, and N. Magan (Wallingford: CAB International). fermentation media and parameter experiment and prepared the nematode samples. JZ, JL, and SZ analyzed the data, with the help of BX. SZ and JZ wrote the manuscript. SZ, YG, JZ, and BX revised and approved the final manuscript. All authors contributed to the article and approved the submitted version.

\section{FUNDING}

This work was supported by a Research Program sponsored by the Gansu Provincial Key Laboratory of Aridland Crop Science, Gansu Agricultural University (project GSCS-2017-1); Special Funds for Discipline Construction (project GAU-XKJS-2018-147); Scientific Research Start-up Funds for Openly-recruited Doctors (project 2017RCZX07); the National Natural Science Foundation of China (project 31860526); the Gansu Provincial Science Fund for Distinguished Young Scholars (project 18JR3RA161); the International Scientific and Technological Cooperation of Gansu Province (project 1604WKCA010); and the Hall of Gansu Province Farming Herd Biology Technology (project GNSW-2013-19).

Khan, A., Williams, K. L., and Nevalainen, H. K. M. (2004). Effects of Paecilomyces lilacinus protease and chitinase on the eggshell structures and hatching of Meloidogyne javanica juveniles. Biol. Control 31, 346-352. doi: 10.1016/j. biocontrol.2004.07.011

Khan, T. A., and Saxena, S. K. (1997). Effect of root-dip treatment with fungal filtrates on root penetration, development and reproduction of Meloidogyne javanica on tomato. Int. J. Nematol. 7, 85-88.

Larentis, A. L., Nicolau, J. F., Esteves Gdos, S., Vareschini, D. T., de Almeida, F. V., dos Reis, M. G., et al. (2014). Evaluation of pre-induction temperature, cell growth at induction and IPTG concentration on the expression of a leptospiral protein in E. coli using shaking flasks and microbioreactor. BMC Res. Notes 7:671. doi: 10.1186/1756-0500-7-671

Li, Y., Liu, Z., Zhao, H., Xu, Y., and Cui, F. (2007). Statistical optimization of xylanase production from new isolated Penicillium oxalicum ZH-30 in submerged fermentation. Biochem. Eng. J. 34, 82-86. doi: 10.1016/j.bej.2006. 11.011

Li, Y. Q., Song, K., Li, Y. C., and Chen, J. (2016). Statistical fermentation-based strategies to enhance chlamydospore production by Trichoderma harzianum SH2303 in liquid fermentation. J. Zhejiang Univ. Sci. B 17, 619-627. doi: 10.1631 /jzus.b1500226

Long, H. B., Peng, H., Huang, W. K., Wang, G. F., Gao, B. L., Moens, M., et al. (2012). Identification and molecular characterization of a new $\beta-1$, 4-endoglucanase gene (Ha-eng-1a) in the cereal cyst nematode Heterodera avenae. Eur. J. Plant Pathol. 134, 391-400. doi: 10.1007/s10658-012-9 997-1

Meyer, S. L. F., Huettel, R. N., Liu, X. Z., Humber, R. A., Juba, J., and Nitao, J. K. (2004). Activity of fungal culture filtrates against soybean cyst nematode and root-knot nematode egg hatch and juvenile motility. Nematology 6, 23-32. doi: 10.1163/156854104323072883

Meyer, S. L. F., Roberts, D. P., Chitwood, D. J., Carta, L. K., Lumsden, R. D., and Mao, W. (2001). Application of Burkholderia cepacia and Trichoderma virens, alone and in combinations, against Meloidogyne incognita on bell pepper. Nematropica 31, 75-86.

Mukhtar, T., Kayani, M. Z., and Hussain, M. A. (2013). Nematicidal activities of Cannabis sativa L. and Zanthoxylum alatum Roxb. against Meloidogyne incognita. Ind. Crop Prod. 42, 447-453. doi: 10.1016/j.indcrop.2012.06.027

Nicol, J., Rivoal, R., Taylor, S., and Zaharieva, M. (2003). Global importance of cyst (Heterodera spp.) and lesion nematodes (Pratylenchus spp.) on cereals: 
distribution, yield loss, use of host resistance and integration of molecular tools. Nematol. Monogr. Perspect. 2, 1-19.

Nicol, J. M., and Rivoal, R. (2008). "Global knowledge and its application for the integrated control and management of nematodes on wheat," in Integrated Management and Biocontrol of Vegetable and Grain Crops Nematodes, eds A. Ciancio and K. G. Mukerji (New York: Springer Press), 251-294.

Nitao, J. K., Meyer, S. L. F., Olive, J. E., and Chitwood, D. J. (2002). Isolation of falvipin, a fungus compound antagonistic to plant parasitic nematodes. Nematology 4, 55-63. doi: 10.1163/156854102760082203

Niu, W., Wang, X., Li, H., Ju, Y., and Wan, W. (2016). Duplex-PCR detection for Heterodera avenae and $H$. filipjevi based on mtDNA-COI sequences. Sci. Agric. Sin. 49, 1499-1509.

Peng, D. L., Nicol, J. M., Li, H. M., Hou, S. Y., Li, H. X., Chen, S. L., et al. (2009). "Current knowledge of cereal cyst nematode (Heterodera avenae) on wheat in China," in Cereal Cyst Nematodes: Status, Research and Outlook, eds I. T. Riley, J. M. Nicol, and A. A. Dababat (Ankara: CIMMYT), 29-34.

Sergio, M. (2011). Natural genetic and induced plant resistance, as a control strategy to plant parasitic nematodes alternative to pesticides. Plant Cell Rep. 30, 311-323. doi: 10.1007/s00299-010-0972-z

Sharma, A., Sharma, S., and Dalela, M. (2014). Nematicidal activity of Paecilomyces lilacinus 6029 fermentationd on Karanja cake medium. Microb. Pathog. 75, 16-20. doi: 10.1016/j.micpath.2014.08.007

Sharma, S., Kuila, A., and Sharma, V. (2017). Enzymatic hydrolysis of thermos chemically pretreated biomass using a mixture of cellulolytic enzymes produced from different fungal sources. Clean Technol. Envir. 19, 1577-1584. doi: 10. 1007/s10098-017-1346-9

Sharon, E., Chet, I., Viterbo, A., Bar-Eyal, M., Nagan, H., Samuels, G. J., et al. (2007). Parasitism of Trichoderma on Meloidogyne javanica and role of the gelatinous matrix. Eur. J. Plant Pathol. 118, 247-258. doi: 10.1007/s10658-007-9140-x

Sharon, E. C. I., Bar-Eyal, M., Chet, I., Herrera-Estrella, A., Kleifeld, O., and Spiegel, Y. (2001). Biological control of the root-knot nematode Meloidogyne javanica by Trichoderma harzianum. Phytopathology 91, 687-693. doi: 10.1094/phyto. 2001.91.7.687

Siddiqui, Z. A., and Mahmood, I. (1996). Biological control of plant parasitic nematodes by fungi: a review. Bioresource Technol. 58, 229-239. doi: 10.1016/ s0960-8524(96)00122-8

Smiley, R. W., Whittaker, R. G., Gourlie, J. A., Easley, S. A., and Ingham, R. E. (2005). Plant-parasitic nematodes associated with reduced wheat yield in Oregon: Heterodera avenae. J. Nematol. 37, 297-307.

Spiegel, Y., and Chet, I. (1998). Evaluation of Trichoderma spp. as a biocontrol agent against soilborne fungi and plant-parasitic nematodes in Israel. Integr. Pest Manag. Rev. 3, 169-175.

Suarez, B., and Llobell, A. (2004). Isolation and characterization of PRA1, a trypsinlike protease from the biocontrol agent Trichoderma harzianum CECT 2413 displaying nematicidal activity. Appl. Microbiol. Biotechnol. 65, 46-55.
Trupkin, S., Levin, S., and Forchiassin, F. (2003). Optimization of a fermentation medium for ligninolytic enzyme production and synthetic dye decolorization using response surface methodology. J. Ind. Microbiol. Biot. 30, 682-690. doi: 10.1007/s10295-003-0099-0

Wang, Y. J., Zhang, J., Kong, F. F., Nan-Gong, Z. Y., Song, P., and Wang, Q. Y. (2014). Screening of original medium and optimizing fermentation conditions of Xenorhabdus nematophila HB310. J. Environ. Entomol. 36, 997-1003.

Wiater, A., and Szczodrak, J. (2001). Selection of method for obtaining an active mutanase preparation from Trichoderma harzianum. Biotechnol. Lett. 23, 427-431.

Yan, Z. L., Cao, X. H., Liu, Q. D., Yang, Z. Y., Teng, Y. O., and Zhao, J. (2012). A shortcut to the optimization of cellulase production using the mutant Trichoderma reesei YC-108. Indian J. Microbiol. 52, 670-675. doi: 10.1007/ s12088-012-0311-x

Yang, C. X., Zhao, D., Tan, Z., Zhu, X. F., Liu, X. Y., Duan, Y. X., et al. (2016). Ferment optimization of biocontrol fungus Snef5 against Meloidogyne incognita by response surface methodology. Chin. J. Biol. Control 32, 503-510.

Yang, J., Tian, B., Liang, L., and Zhang, K. Q. (2007). Extracellular enzymes and the pathogenesis of nematophagous fungi. Appl. Microbiol. Biot. 75, 21-31. doi: 10.1007/s00253-007-0881-4

Yu, Z., Zhang, Y. C., Zhang, X., and Wang, Y. (2015). Conversion of food waste into biofertilizer for the biocontrol of root knot nematode by Paecilomyces lilacinus. Environ. Technol. 36, 3148-3158. doi: 10.1080/09593330.2015.1055817

Zhang, S. W., Gan, Y. T., Ji, W. H., Xu, B. L., Hou, B. H., and Liu, J. (2017). Mechanisms and characterization of Trichoderma longibrachiatum T6 in suppressing nematodes (Heterodera avenae) in wheat. Front. Plant Sci. 8:1491. doi: 10.3389/fpls.2017.01491

Zhang, S. W., Gan, Y. T., and Xu, B. L. (2015). Biocontrol potential of a native species of Trichoderma longibrachiatum against Meloidogyne incognita. Appl. Soil Ecol. 94, 21-29. doi: 10.1016/j.apsoil.2015.04.010

Zhang, S. W., Gan, Y. T., Xu, B. L., and Xue, Y. Y. (2014). The parasitic and lethal effects of Trichoderma longibrachiatum against Heterodera avenae. Biol. Control 72, 1-8. doi: 10.1016/j.biocontrol.2014.01.009

Conflict of Interest: The authors declare that the research was conducted in the absence of any commercial or financial relationships that could be construed as a potential conflict of interest.

Copyright (c) 2020 Zhang, Gan, Liu, Zhou and Xu. This is an open-access article distributed under the terms of the Creative Commons Attribution License (CC BY). The use, distribution or reproduction in other forums is permitted, provided the original author(s) and the copyright owner(s) are credited and that the original publication in this journal is cited, in accordance with accepted academic practice. No use, distribution or reproduction is permitted which does not comply with these terms. 